\title{
DEVELOPMENT MODEL FOR SUPPORTING THE ACCOMPLISHMENT OF ACADEMIC LEVEL: CASE STUDY OF BINA NUSANTARA UNIVERSITY
}

\author{
Sulistyo Heripracoyo ${ }^{1}$; Wawan Saputra ${ }^{2}$; Wince $^{3}$ \\ Information System Department, School of Information System, Bina Nusantara University \\ Jln. K. H. Syahdan No. 9, Jakarta 11480, Indonesia \\ 1hpracoyo@binus.edu; ${ }^{2}$ wawans@binus.edu; 33ince@binus.edu
}

\begin{abstract}
The fact that a small number of lecturers who are able to meet or pass the requirements for obtaining or enhancing the academic hierarchy (JJA/Jenjang Jabatan Akademis) is the reason of the study. An analysis was performed on the historical data of the university faculty members. Analysis of historical data was done by making use of a data warehouse and data mining applications to describe and map lecturer's JJA care, as well as with the data mining tool WEKA version 3.6.6. to know some of the variables that affect the maintenance of the JJA at Bina Nusantara University. Results of this study are most between the ages of 30 and 45 years old, and for analysis based on a paper having an excellent outcome is the level of lecturer (Lektor) and Associate Professor. Based on these results, it needs special attention especially those aged between 30 and 45 and who have JJA Associate Professor and Lecturer (Lektor).
\end{abstract}

Keywords: JJA; Lecturer; Data Warehouse; Data mining

\section{INTRODUCTION}

Lecturer is clearly an important resource in a university [1]. Roles, duties, and responsibilities of the lecturer are very significant in achieving national education goals, the intellectual life of the nation, and improving the quality of Indonesian people. The function and role require a professional lecturer. Professional itself can be expressed as the work or activity performed by a person and a source of income that requires skill, expertise, or skills that meet certain quality standards or norms and requires professional education. Evidence of lecturer professionalism and a form of execution is in the Tridharma decision letter (SK) on the functional level of a lecturer or academic hierarchy (JJA). It is recognition from the government in the form of cumulative value of the education grain, research and community service made by the lecturer at a certain period. BINUS University appreciates the efforts made by the lecturer to acquire SK JJA. For that, the institution will provide compensation and benefits to the lecturers who have successfully taken care of the JJA, which can be academic incentive, academic allowance each month, adjustment, listed as old-age insurance participants (SIHARTA), scholarship, or to facilities their two legitimate children.

Despite all of the facilities provided by the institution are very easy, there are a few lecturers still struggling to raise the JJA. The results of the assessment by the institution assisted in processing less significant, although the opportunity, guidance, coaching and motivation have been conducted. Based on data from database, the nomination of academic hierarchy submission held on May 28th, 2008 was only $16.4 \%$ of 225 that can complete and qualify for a pass at the time of assessment from the Kopertis assessment team. In the period of the nomination of academic hierarchy submission in 2009 , it was recorded only $19 \%$ of the 244 that can complete and qualify to pass the assessment from the Kopertis assessment team.

Why the JJA is still lack of maintenance by the lecturers and what factors are leading to low interest in academic hierarchy members while the supporting factors are available are the problems observed. Some of the main problems for the study are the obstacles to the maintenance of academic lecturer rank increase and how the institution can obtain timely and accurately the information about the factors affecting the care of the lecturers about JJA. In an effort to address the problems that arise, it is necessary tasks that are part of the objectives of this study. It is to find out what the factors that inhibit the increase in faculty academic rank. The study was conducted to analyze the lecturer data, to create a data warehouse and was analyzed using data mining to determine the factors that influence 
lecturers in taking care of the academic hierarchy. To institution, it can be an input relating to factors that affect the lecturers in taking care of the increase levels of academic lecturers; and it is to predict the lecturers who will qualify the JJA and also to assist in decision making.

\section{Literature Review}

\section{Data Warehouse and Data Mining}

Many organizations or companies that have for years been using the application to manage data and information (Online Transaction Processing/OLTP), the resulting data will be large and complex [2]. Associated with the greater data and the technology used are different from previous years, then the question will arise is how to manage the data (database) in large numbers and the technology used is different [2]. One solution that can be given is to create/design a data warehouse. According to Inmon [2], a data warehouse has four important characteristics. They are subjectoriented, integrated, nonvolotile and time-variant. Subject-oriented is existing data in the data warehouse subject oriented, not oriented to the transactional (applications). Integrated is the data in the data warehouse comes from many different sources/apart to be integrated into the data warehouse. Nonvolotile is data in the data warehouse update is only done statically by simply inserting data (snapshots), and not changing/updating the data warehouse. Timevariant is the data in the data warehouse will only be accurate at one moment of time. There are five stages of decision-making in the data warehouse. They are: 1) the stage of reporting (reporting), 2) analyzing phase (analysis), 3) predicting stage (predict), 4) operationalizing stage (operation), 5). Warehousing active phase [3]

In practice, the two main objectives of data mining tend to prediction and description [4]. Predictions include using some variables or fields in the data set to predict unknown or future value of the variable that matters. Descriptions focus on finding a pattern that describes the data that can be interpreted by humans, which further data-mining activities can be divided into two categories. Predictive data mining is to generate a model of the system described by a given data set. Descriptive Data mining generates new information, nontrivial, based on the available data sets.

Data warehouse and data mining is used to extract useful information and have some sense and to develop a real relationship between the number of variables stored in data/data warehouse [5]. A data warehouse is designed and added to the right to give an appropriate data needs and useful in making better decisions. With the help of hardware and software that facilitate adequate access to the data, it analyzes and displays the results interactively. Data mining software is a very effective tool that can be used to interrogate the amount of data contained in a data warehouse in order to find the relationship.

The emergence of the data warehouse as a repository advances in data cleansing which leads to a single truth, a greater ability of the hardware and software and the explosion of Internet technology that provides a common user interface that combines all the business intelligence to create enriched environments than previously available [6].

\section{Lecturer and Academic Hierarchy}

Lecturers are professional educators and scientists with the main task to transform, develop and disseminate the science, technology and arts through education, research, and community service [7][8]. Credit score is the unit value of each item or activity and the accumulated value of the items given activity/set based on an assessment of the achievements that have been accomplished by a lecturer and used as one of the requirements in order to develop a career in a functional position/rank/academic level of the position [9].

\section{METHOD}

This study began with gathering data from the lecturers who take JJA period 2004 to 2012. Data for 2012 were taken with the recent data in August 2012. Furthermore, the data were processed to make schema and data warehouse structure. Based on data from the data warehouse, lecturer data were analyzed using descriptive analysis, and also were analyzed to find a description and map of lecturers who take JJA. In addition the data were analyzed by using data mining, as illustrated in Figure 1. With data mining data lecturers who take care of JJA analyzed to determine some of the variables that affect the management of JJA. The variables to be considered in analyzing the data history include Age, Education, Gender, Study of Education, Department of Education.

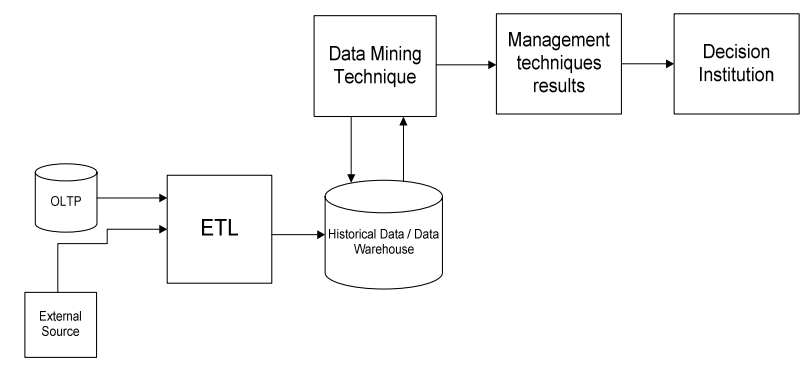

Fig 1: Research Model 


\section{Data Analysis}

Data were analyzed using descriptive analysis, data warehousing, OLAP as illustrated in Figure 2 and data mining software using analytical models Tree. Descriptive data from data analysis can be seen in Figure 3.

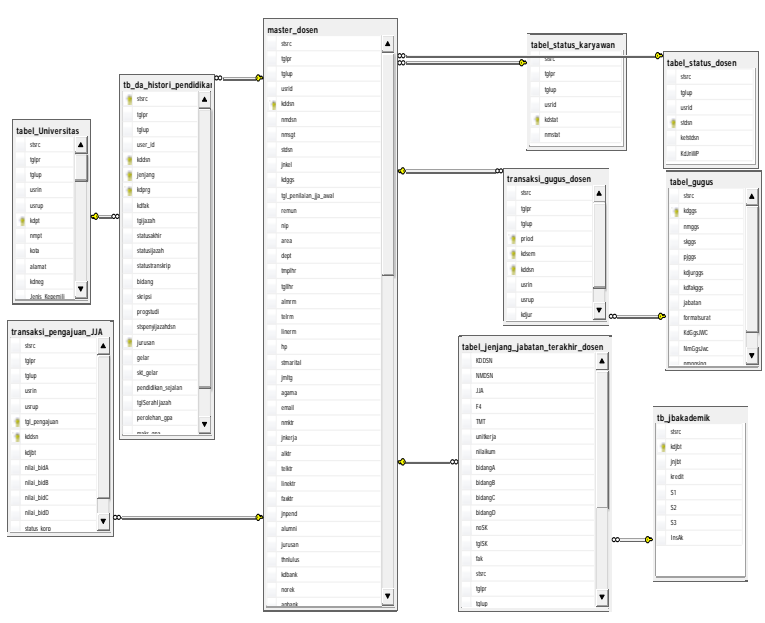

Fig 2: OLTP Structure

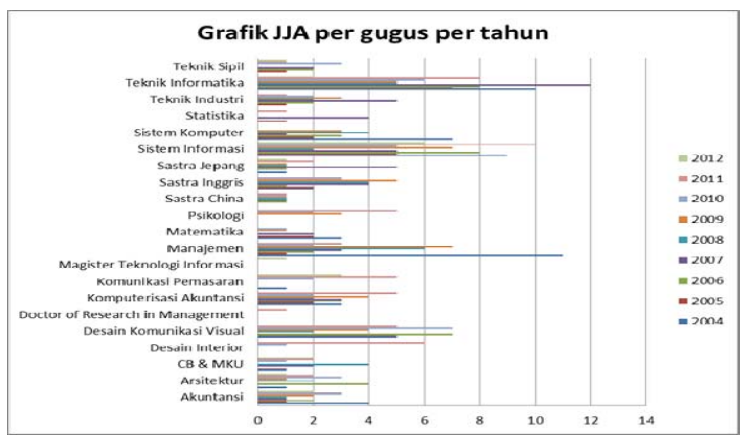

Fig 3: JJA Graphic per Group and Year

Data warehouse is generally made with one large centralized fact tables, dimension tables and a few smaller ones. This configuration is commonly referred as a star schema. A star schema was used in this study. Below is a diagram of the relationship between the fact tables and dimension tables. The data from the OLTP will be ETL (Extract, Transform, Load) into fact and dimension tables.

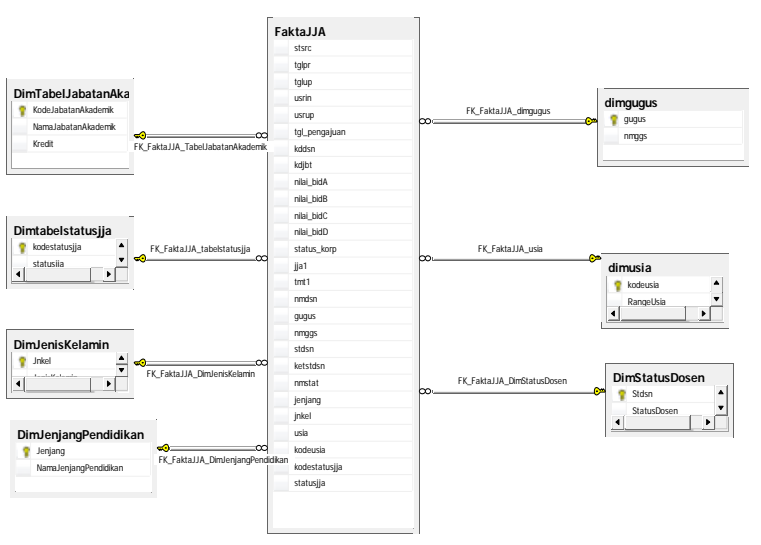

Fig 4: Data Warehouse Structure

Based on the analysis of the data, the following is the structure diagram of the data warehouse which is used to hold the results of the data that have been processed and transformed into the tables as illustrated in Figure 4. Furthermore, the data in the data warehouse are taken in accordance with the needs and further analyzed by a data mining technique. Tool used in the data mining was software WEKA version is 3.6.6. (Open source software). Data from the data warehouse were transformed into a file in CSV format, and then file with CSV format was opened with WEKA ARFF Viewer. With the WEKA, the data were analyzed with the Model Tree, by selecting the Filter Unsupervised RepTree models and Model Tree (J48) as illustrated in Figure 5 and Figure 6 as follows.

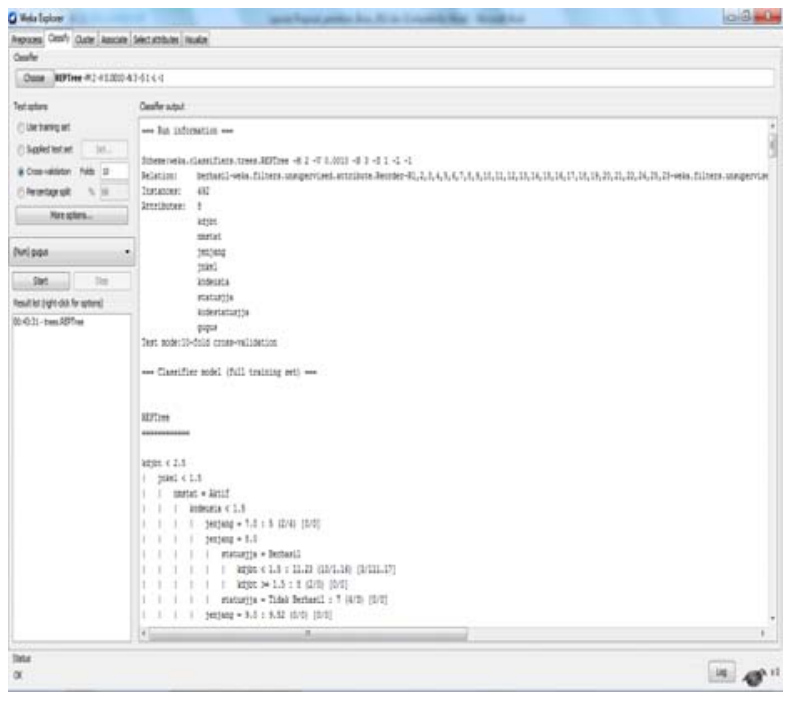

Fig 5: WEKA Run Information 


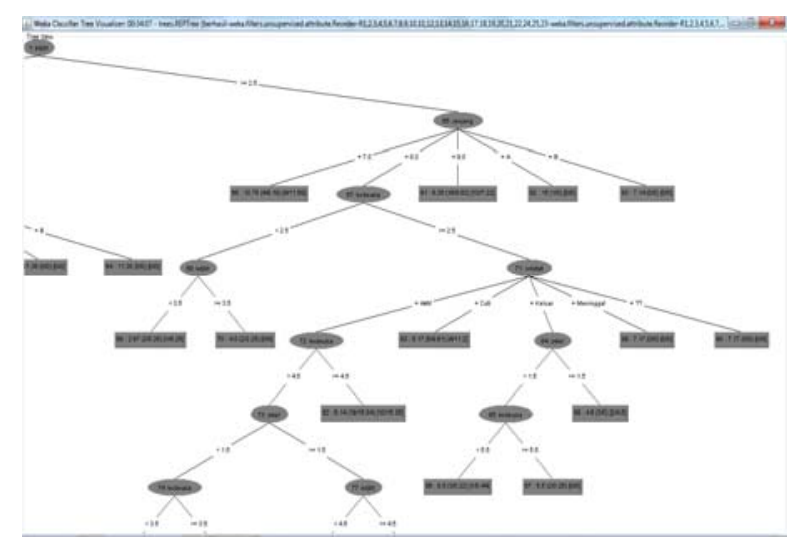

Fig 6: Tree of Analysis Result

\section{RESULTS AND DISCUSSION}

The results using the WEKA application to the data are as follows. Using J48, the figure shows for correctly classified instances are 400 (81.3008\%) and incorrectly classified instances are 92 (18.6992\%). False positive rate is also low. It was measured by classification based on written papers.

While based on applications using RepTree WEKA, the attribute Study Function, Gender, Status Lecturer, Study of Education, JJA Status can be explained as follows. Active lecturers aged 2030 years old and S2 educated and successful at the JJA are 11:23. Expert Assistant position, the expert assistants are eight, aged 30 years old and less than 45 years old with S2 degree, the rank is 10:33 in taking JJA, which is unsuccessfully is 8.36. While the post of assistant professor and above, for ages less than 30 years old is 5.45 , and above 35 years is 9:18, and S3 is as much as 9.67. For the age of 45 years old is 9.1, for the status on leaves, the JJA for S1 is 7 and S2 is 8, which does not work is 15 . For female taking JJA, active status, less than 30 years old is 13.87, above 30 years and less than 35 years 10.64 and above 35 years with the rank of assistant expert 10.89, and above the expert assistant 12. For those aged over 35 years are 13:56, for a Lectureship position is 9.56 , the status on leaves 9:56, and for those out 7.67.

While for the post of Lector and so on, if S2 and under 35 years old and on lector position is 2.67 , above the lector is 4.5 , being over the age of 35 years old, active status and age under 45 years and under 35 year, male is 9.38 and above 35 years is 7.8 .

Meanwhile, if analyzed by papers/paperlisting, where scientific papers are classified based on the value of the credit: $0=$ Poor, $1-20=$ Minimal, $>20-<50=$ Enough, $>50$ and less than $100=$ Good, $>100=$ Very good. The analysis done is, if Qualification Function is expert assistant the paper is then generated still minimal, to Qualification Lector position papers produced distinguished by their education, if education S1 results generated paper is Enough $=3$, Good $=3$ and very good $=2$. For S2 produced both papers. As for those having Qualification Function head of lector and then, which are still active and have a good outcome are 36, who are on leaves and have a good result are 4 , which are out and very good $=4$. As for the paper that has quite a lot of bad results, as it relates to the status of the management that has not been successful, where the position code $<=$ 0 indicates that the lecturers have not received JJA.

Based on the status of the successful JJA associated with the paper, it could be explained that the level of the position for Assistant Expert (100) total 94 with minimal paper status, to the assistant expert (150), could be explained as follows, Assistant expert lecturers status FM 150 with Structural, FM, FMSCS and Associate Faculty Member has a poor outcome paper. For Non Adjuct Homebes paper results are minimal. For JJA Lector (200) result can be explained as follows, JJA lectors and lecturer with status Structural FM, FM has a poor outcome paper, while FMSCS, Associate FM and part-time have enough paper results. For non home base adjunct lecturers' status under the age of 45 years have a good outcome, while for the age of 45 years the results of papers are enough. For JJA Lector (300) and so on, JJA Lector $(300,400)$ has a good outcome paper. Head of lector (550) and above have a very good paper results.

Answers of the questions on this study about why the maintenance of JJA by lecturers is very little and what factors affect, from the results of data analysis, they are (1) factor of outcome papers (poor, minimal, enough, good, very good), (2) age factor, (3) lecturers who have JJA.

\section{CONCLUSION}

Based on the analysis process performed, it could be explained that the critical success factors to the JJA include the relationship between some factors and other factors. From the data to predict the success of taking JJA in accordance with the results of a process that has been carried out using data mining and WEKA primarily by age and sex, as well as the research/paper to have all JJA is at most between 30 and 45 years old. For analysis based on paper having an excellent outcome JJA is the level of Lector and head of lector. Based on these results, it needs special attention especially those aged between 30 and 45 years old and those who have Lector and associate professor. 


\section{ACKNOWLEDGMENT}

Thank you for Bina Nusantara University which has provided the opportunity and the funding to perform the study.

\section{REFERENCES}

[1] Pemerintah Republik Indonesia, Peraturan Pemerintah Republik Indonesia, Nomor 37 tentang Dosen, 2009.

[2] W. H. Inmon, Building the Data Warehouse, 3rd Ed., Canada: John Wiley \& Sons, 2002.

[3] K. G. Akintola, A. O. Adetunmbi, \& O. S. Adeola, "Building Data Warehousing and Data Mining from Course Management Systems: A Case Study of FUTA Course Management Information Systems”, International Journal of Database Theory and Application, 4(3), Sept. 2011.

[4] M. Kantardzic, Data Mining: Concepts, Models, Methods, and Algorithms, New Jersey, USA: IEEE Press, WileyInterscience, 2003.

[5] R. Neary, "Building a Data Warehouse and Data Mining for a Strategic Advantage", The Journal of Information Technology Theory and Application (JITTA), 1(1), pp. 7-21, 1999.

[6] S. Negash, "Business Intelligence", Communications of the Association for Information Systems, 13, pp. 177-195, 2004.

[7] S. P. Siagian, Filsafat Administrasi, Jakarta: Gelora Aksara Pratama, 1990.

[8] Undang-undang Republik Indonesia, Nomor 14 Tahun 2005, tentang Guru dan Dosen.

[9] Menteri Pendidikan Nasional, Keputusan Menteri Pendidikan Nasional Nomor: 36/D/O/2001, tentang Petunjuk Teknis Pelaksanaan Penilaian Angka Kredit Jabatan Dosen. 